\title{
PERIODISMO
}
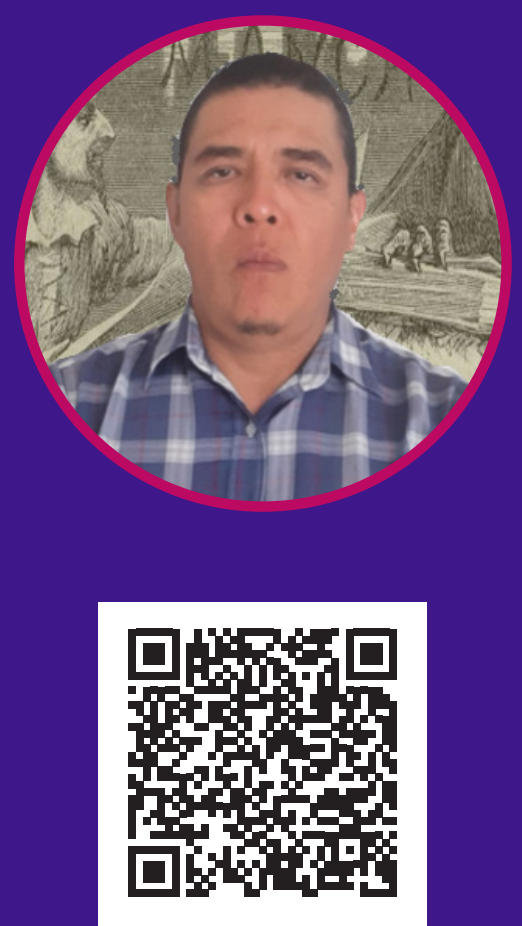

Videopresentación

\section{La cobertura informativa al Tercer Centenario de El Ingenioso Hidalgo Don Qufjote de la Mancha en la prensa mexicana(1903-1905)}

\author{
The informative coverage of the Third Centennial of El Ingenioso \\ Hidalgo Don Quijote de la Mancha in the Mexican press (1903-1905)
}

\author{
Dr. Iván B. Vázquez Clavellina \\ Western University (Canadá), Investigador independiente \\ ivazquez@uwo.ca, ORCID: https://orcid.org/0000-0001-9412-2014
}

Recibido: 4 de agosto de 2021.

Received: August 4th, 2021.

Aceptado: 31 de agosto de 2021.

Accepted: August 31st, 2021.

Publicado: 30 de noviembre de 2021.

Published: November 30th, 2021.
DOI: https://doi.org/10.21555/rpc.vi2.2437

Cómo citar: Vázquez Clavellina, I. B. . (2021). La cobertura informativa al Tercer Centenario de El Ingenioso Hidalgo Don Quijote de la Mancha en la prensa mexicana (1903-1905). RPC, (2), 62-71. https://doi.org/10.21555/rpc.vi2.2437

Revista Panamericana de Comunicación, Año 3, N. 2, julio-septiembre 2021, pp. 62-71
RESUMEN

En mayo de 1905 se celebraron tres siglos de la publicación de la primera edición de El Ingenioso Hidalgo Don Quijote de la Mancha. La propuesta de celebrar el tercer centenario fue promovida inicialmente en la prensa por periodistas e intelectuales en España y posteriormente en México. El siguiente artículo analiza la cobertura informativa al tercer aniversario de la obra en la prensa mexicana. El objetivo fue identificar festejos, ceremonias y concursos a través de notas publicadas en periódicos, semanarios y revistas. Para obtener la información se utilizó el acervo de la Hemeroteca Di- gital Nacional de México (HNDM) y se localizaron notas que tratan la organización del homenaje y las fiestas establecidas por eruditos y funcionarios. Los resultados descubren publicaciones, periodistas y corresponsales que reportaron los festejos, y ayudaron a consolidar a Don Quijote como la obra literaria más importante en lengua castellana durante los primeros años del siglo XX.

Palabras-clave: Don Quijote, celebración tercer centenario, prensa mexicana, periodistas españoles. 


\section{A B STRACT}

In May 1905, The Ingenious Hidalgo Don Quixote de la Mancha celebrated three centuries of its first edition. The proposal to celebrate the book was initially promoted in the press by journalists and editors in Spain and later in Mexico. The following article analyzes news coverage of the book's third anniversary in the Mexican press. The objective was to identify celebrations, ceremonies and contests through articles published in newspapers, tabloids, and magazines. The collection of the digital newspaper library of Mexico (HNDM) provid- ed news about the organization and events established by intellectuals and officials. The results uncover publications, journalists and reporters who informed the celebrations, and helped consolidate Don Quixote as one of the most important literary works in Spanish during the early years of the 20th century.

Keywords: Don Quixote, third centenary celebration, mexican press, spanish journalists.

\section{INTRODUCCIÓN}

En 1905 se celebraron 300 años de la publicación de la primera edición de El Ingenioso Hidalgo Don Quijote de la Mancha. La idea de celebrar el tercer centenario de la primera parte de la obra española correspondió a Mariano de Cavia, quien sugirió en El Imparcial un programa de actos conmemorativos para celebrar al libro español en diciembre de 1903. Su artículo provocó las reacciones favorables de otros periodistas que aprobaron la idea y rápidamente escribieron notas en apoyo en el $A B C$ y El Alma Española (Ferrándiz Lozano, 2004, p. 6). Cabe destacar que la difusión transatlántica de la prensa española y las publicaciones periódicas americanas ayudaron a transmitir información sobre la celebración en España. En México, los editores de diarios replicaron la información de la prensa ibérica y ratificaron la necesidad de festejar "la obra inmortal de Cervantes" ${ }^{\prime}$.

Es preciso acotar que, a partir de la celebración del cuarto centenario de la publicación de la primera edición en 2005, algunos investigadores de la re-

1 Hemeroteca Nacional Digital de México (HNDM), "El Centenario de Don Quijote" en El Diario del Hogar, 23/12/1903, p. 2. cepción de Don Quijote ${ }^{2}$ se han interesado en el estudio de las celebraciones de su primera edición. Sus investigaciones utilizaron como fuentes primarias notas en la prensa, por ejemplo, los trabajos de María Ángeles Chaparro Domínguez: "El humor en la cobertura periodística del III Centenario del Quijote"; "La cobertura española del III Centenario del Quijote"; y "Las celebraciones del III y IV Centenario del Quijote en Hispanoamérica a través de la prensa española de 1905 y 2005". En “El Ateneo de Madrid y el tercer centenario del Quijote en 1905", Eric Storm manifestó que las publicaciones periódicas fueron amplios promotores y difusores de las fiestas pues muchas dedicaron números especiales para enaltecer la primera edición del libro (2008, pp. 11-13). En "La Ilustración Española y Americana ante el Tercer Centenario del Quijote", Antonio Ayuso Pérez determinó que la idea de festejar la primera edición fue amplia-

2 José Montero Reguera denomina la recepción del Quijote como los trabajos de investigación que estudian la lectura y difusión del libro español a lo largo de los siglos: "influencias en otros textos literarios, en obras de arte, en la música: su utilización, según las épocas, como arma política, de crítica literaria, etc.; su difusión y éxito por diversos países (ediciones, traducciones, imitaciones, continuaciones, etc.); su reflejo en teatro, en autores concretos..." (101). 
mente aceptada y divulgada por la prensa: "un ejemplo del enorme poder que los medios de comunicación estaban cobrando de forma imparable" (2007).

Con el fin de contribuir con el estudio de la recepción de Don Quijote en América, el siguiente artículo analiza la cobertura informativa al tercer aniversario en la prensa mexicana. El objetivo fue identificar cómo se cubrieron los festejos a través de notas periodísticas y artículos de opinión. Para ubicar la información se revisó el acervo de la Hemeroteca Nacional Digital de México (HNDM): en el repositorio se localizaron notas publicadas en periódicos, semanarios y revistas. Después de clasificarlas por fecha y separar las repetidas, se analizaron para identificar lugares, personajes y actividades. Se seleccionaron más de veinte textos divididos en dos secciones que tratan la organización del homenaje y las fiestas establecidas por asociaciones intelectuales. Los resultados descubren publicaciones, periodistas y corresponsales que reportaron los festejos, y con su trabajo ayudaron a consolidar a Don Quijote como la obra literaria más importante en lengua castellana a principios de siglo XX.

\section{“NUESTRO HOMENAJE A CERVANTES"}

En "Don Quijote de la Mancha en tierras americanas”, Rafael González Cañal planteó que "al cumplirse el tercer centenario de la publicación de la primera parte del Quijote, se produce un redescubrimiento de la obra cervantina en los distintos países hispanoamericanos". El investigador aseguró que los diversos homenajes renovaron el interés por Cervantes y la obra se ratificó como una de las más importantes de la literatura universal (2016, p. 208). Este redescubrimiento de la obra cervantina fue fomentado en gran medida por la prensa periódica publicada en España y América. El estudio del acervo de la Hemeroteca Nacional Digital de México (HNDM) descubrió como algunas publicaciones refrendaron la idea de celebrar el tercer centenario de la obra de Cervantes entre los lectores mexicanos. Desde diciembre de 1903, la prensa mexicana transmitió notas que reseñaron los preparativos organizados en España, por ejemplo, El Diario del Hogar:

3 El Diario del Hogar circuló en la Ciudad de México bajo la dirección del
En el próximo año de 1905 se cumplirá el tercer centenario de la publicación de la obra inmortal de Cervantes, Don Quijote de la Mancha, a trescientos años que el ingenioso hidalgo anda corriendo por tierras de España y de América, desafiando agravios, enderezando entuertos y enseñando tantas buenas cosas que estaban ignoradas 4 .

Según la nota en El Diario del Hogar, "la Academia Española y no pocos escritores comenzaron a preocuparse por la manera de celebrar la fecha". El editor señaló que se pensaron distintas cosas para honrar al "alma mater del espíritu nacional español", por ejemplo, publicar una nueva edición monumental de la obra de Cervantes, y "otra popular que pueda llevar a todos los rincones de España la luz de los razonamientos del hidalgo manchego" ${ }^{\prime 5}$. La revisión en la prensa documenta que los acontecimientos dieron la oportunidad a muchos periodistas para difundir sus propios planes y las rivalidades entre grupos estuvieron presentes. En "The Generation of 1898 and Cervantes: The invention of Don Quixote as a national symbol", Eric Storm reveló que las luchas políticas influyeron en las conmemoraciones y las celebraciones oficiales en España estuvieron a cargo de pensadores afines a la derecha española (2015, p. 363).

Durante los primeros meses de 1904 las notas en la prensa mexicana sobre los preparativos a la celebración se multiplican. La revisión hemerográfica dejó de manifiesto que los editores y reporteros monitorearon los diarios españoles y elaboraron reseñas para los lectores mexicanos, por ejemplo, La Patria ${ }^{6}$ reportó la reunión de la comisión encargada de organizar los festejos en el Ayuntamiento de Madrid. La nota no está

profesor y periodista Filomeno Mata. La Hemeroteca resguarda copias digitales desde el 16 de septiembre de 1881 hasta el 30 de junio de 1912. Su encabezado lo describía como el "Periódico de las familias".

4 HNDM, "El Centenario de Don Quijote" en El Diario del Hogar, 23/12/1903, p. 2.

5 Ibid., p. 2.

6 La publicación se imprimió por primera vez el 16 de marzo de 1877, su editor, director y redactor fue Irineo Paz. Se describió como "Diario político, científico, literario, comercial y de anuncios". Circuló en la Ciudad de México hasta el 26 de agosto de 1914. 
firmada y seguramente fue escrita por Ireneo Paz quien fungió como editor de la publicación. En esa ocasión se alabó a los españoles por celebrar "el más grande de los episodios de su historia literaria", y se enalteció las biografías de Cervantes elaboradas por Pellicer, Juan de Iriarte y Martín Fernández de Navarrete: "eruditísimas investigaciones históricas hasta poner en claro la vida y hechos del gran hombre”. Se recalcó su carácter universal pues "Cervantes no es sólo español: es un genio universal como Esquilo entre los de la época antigua, como Shakespeare entre los del siglo XVI, como Zola en la actualidad". El editor de la nota recomendó que "las repúblicas hispanoamericanas" celebren la fecha "porque constituye un motivo de orgullo para todos los que, aunque políticamente separados con el nombre de mexicanos, españoles, peruanos, etc., nos sentimos fuertemente enlazados por la lengua de oro en que se escribió el Quijote"7.

Entre las publicaciones más activas estuvo El Diario del Hogar, pues en distintas notas replicó las propuestas de la Real Academia Española y otras agrupaciones de intelectuales, por ejemplo, en "El centenario de Don Quijote" reportó las ideas de los organizadores como publicaciones abreviadas para institutos de primera y segunda enseñanza; ediciones críticas de algunas de "las obras menores de Cervantes"; representaciones teatrales de pasajes del libro; la restauración de la capilla donde se bautizó Miguel de Cervantes; la creación del Museo Biblioteca Cervantes en Alcalá de Henares; el establecimiento del Instituto Cervantes; la organización de conferencias académicas; la construcción del "Palacio de Cervantes"; un certamen musical inspirado en el libro; una procesión o cabalgata novelesca con escenas del Quijote; y una medalla conmemorativa del centenario ${ }^{8}$.

Otro periódico que cubrió los preparativos al tercer centenario del Quijote fue La Voz de Mexico ${ }^{9}$. En

7 HNDM, "Una fiesta nacional. El centenario de Quijote" en La Patria, 2/06/1904, 1 .

8 HNDM, "El centenario de Don Quijote" en El Diario del Hogar, 21/07/1904, 1.

9 Según el HNDM, La Voz de México se imprimió en la ciudad de México desde el 17 de abril de 1870 hasta el primero de diciembre de 1908. Fue fundado por "La Sociedad Católica" con el objetivo de defender la religión católica y contrarrestar la prensa liberal y protestante. Su lema fue: "Diario político, Religioso, científico, y Literario de la Sociedad Católica”.
Agosto de 1904, informó sobre la celebración programada para el mes de mayo de 1905. El reportero refirió que se va a celebrar "la obra modelo de la lengua castellana en todas las naciones donde se habla el idioma de Cervantes", y pronosticó que "el centenario del Quijote superará en mucho al segundo centenario de la muerte, de Don Pedro Calderón de la Barca, realizado hace ya veintidós años, y al cuarto del descubrimiento del Nuevo Mundo, once años ha"10. La nota anterior es un buen ejemplo de cómo la prensa periódica cubrió las distintas celebraciones para honrar y enaltecer a los hombres de letras y fechas importantes. Es preciso destacar que los periodistas y editores a su vez son lectores de obras literarias: con sus noticias, críticas y reseñas ayudan con los procesos de recepción pues sus opiniones atraen nuevos lectores y sus escritos preservan en las publicaciones periódicas autores y personajes.

La información procedente de España influyó en algunos articulistas mexicanos que al leer los preparativos en diferentes partes del mundo lanzaron llamamientos a la comunidad cultural a festejar el centenario en México. En El Contemporáneo ${ }^{11}$, K. Milos preguntó: "¿Permaneceremos nosotros mudos ante un hecho de semejante naturaleza?". El articulista hizo una Ilamada a "la juventud que piensa y crea" en el campo de las letras y les cuestionó si dejarán pasar una fecha tan importante "que dio al mundo tamaño motivo para meditar, tanto pretexto para reír, ocasión sobrada para llorar y la mejor escuela para aprender". Llamó a las nuevas generaciones a "tributar los honores merecidos, aunque póstumos, al príncipe de esa literatura que rodando de siglo en siglo perdura y se conserva fresca y galana". Consideró al Quijote como "la joya más rica de una raza que, aunque desaparezca en la evolución transformadora de los siglos, dejará esa herencia para civilización de sus naturales descendientes", y lanzó el reto a "los que estudian, los que anhelan alto, los que viven en el porvenir, mirando siempre las grandezas del pasado, no se condenen a un mutismo que no estaría justificado bajo ningún concepto"12.

\footnotetext{
10 HNDM, “De Todo el Mundo" en La Voz de México, 20/08/1904, 2.

11 La publicación apareció en San Luis Potosí, las copias digitales están disponibles desde el 10 de marzo de 1897 hasta el primero de junio de 1909. Se denominó como "Diario Independiente" y estuvo a cargo de M. Esquivel y Cía.

12 HNDM, “A la juventud estudiosa. El centenario de Don Quijote" en El
} 
Los Ilamados a celebrar la primera edición del Quijote fueron escuchados por agrupaciones culturales mexicanas, y al igual que en España se nombraron comisiones que se encargaron de los eventos y concursos, por ejemplo, la Revista Moderna de México ${ }^{13}$ notificó la convocatoria al concurso Literario organizado por el Liceo Altamirano:

$$
\mid
$$

... deseando solemnizar debidamente el tercer centenario de la publicación del Quijote, y contando con la ayuda del Supremo Gobierno de la Republica y de varias corporaciones y personalidades, ha determinado abrir un concurso literario, para cuyo lucimiento convoca por la presente a todos los escritores del país ${ }^{14}$.

Antonio Saborit señaló que Liceo Altamirano lo conformó un círculo de intelectuales que se reunían en restaurantes de la capital mexicana en compañía del abogado Joaquín D. Casasús. En "El Club Modernista. Relatos de una pasión americana”, aseguró que "tan pronto como se conoció la convocatoria del Liceo Altamirano se sumaron a ella la subsecretaría de Instrucción Pública y el diario El Imparcial" (2006, p. 283). La agrupación literaria avisó que los temas de los certámenes abarcaron la "Influencia del Quijote en el pensamiento hispanoamericano", "Los esfuerzos en pro de unidad y pureza de nuestra lengua", "Cuento relativo a la época y a la vida de Miguel de Cervantes Saavedra” y "La mujer en la obra de Cervantes"15.

Por otra parte, el periódico La Patria avisó que "las sociedades literarias, la prensa, y en general todos los hombres de letras mexicanos "celebrarán el centenario, al igual que en España en donde se prepara un fes-

Contemporáneo, 10/03/1905, 2.

13 La Revista Moderna de México se publicó en la Ciudad de México de 1903 a 1911. Fue una publicación periódica literaria editada por Jesús E. Valenzuela. Adela Pineda Franco refirió que los lectores de la publicación lo conformaban un reducido grupo de hombres cultos: "un sector afluente, competente, citadino, persuadido de la prosperidad del régimen y convencido de su participación en una cultura cosmopolita” (2006, p. 157).

14 HNDM, "El centenario del Quijote" en Revista Moderna de México, 01/02/1905, 47 .

15 Ibid., 47. tival suntuoso". Se hizo notar que el concurso fue bien visto por el rey de España quien mandó "un lujosísimo ejemplar de la obra maestra de Cervantes con el que premiaría uno de los trabajos ganadores del concurso que el Liceo Altamirano abrió". Se aseveró que la distinción de Alfonso XIII para las letras mexicanas "contribuirá a que cada día sean más hondas las simpatías que unan a los dos países"16. La información llegó hasta la ciudad de Hermosillo en Sonora, donde recibieron los informes a través de publicaciones como El Centinela ${ }^{17}$. El semanario comunicó a sus lectores sobre el concurso literario organizado por el Liceo Altamirano: "secundando a las asociaciones literarias de Madrid, Cádiz, Sevilla, Córdoba, Burgos, Salamanca, Barcelona y Alcalá"18.

El concurso literario organizado por el Liceo Altamirano no agradó a algunos periodistas que lo criticaron duramente, por ejemplo, el periódico veracruzano La Opinión ${ }^{19}$ señaló: "Si en política anda nuestro país como anda, es decir, dado a todos los diablos; en ciencias y Bellas Artes anda peor todavía". La nota firmada por "El Corresponsal”, criticó los planes que los "literatos tienen para celebrar pomposamente el tercer aniversario de la aparición de Don Quijote". Afirmó que los encargados no eran muy conocidos, los calificó de presuntuosos pues el concurso literario nacional no tuvo personajes capaces para calificar los trabajos: "todo será copia de temas publicados en la Península Ibérica". La dura crítica fue para los integrantes del comité, pues el autor ratificó que nadie en México es "capaz de acometer la empresa de juzgar, aquilatar con razones propias y glorificar la obra de Cervantes" ${ }^{20}$. Las críticas

16 HNDM, "El Rey de España y las letras mexicanas" en La Patria, 17/03/1905, 1 .

17 El Centinela: periódico político noticioso y de variedades fue un semanario publicado en Sonora y la HNDM resguarda copias digitales desde enero de 1901 hasta diciembre de 1906. Se imprimió en el taller de impresión de R. Bernal en la ciudad de Hermosillo.

18 HNDM, "Concurso Literario" en El Centinela: periódico político noticioso y de variedades, 25/03/1905, 2.

19 La publicación circuló en la ciudad de Jalapa desde el 9 de junio de 1904. Se denominó como "Diario político independiente ", su director fue Francisco $S$. Arias y su jefe de redacción fue José P. Rivera. Se imprimió hasta el 18 de diciembre de 1913.

20 HNDM, "El centenario de Don Quijote y la literatura nacional" en $L a$ Opinión, 25/01/1905, 1. 
no detuvieron los festejos y distintas organizaciones patrocinaron eventos que tuvieron lugar a partir de mayo de 1905.

\section{“LAS FIESTAS DEL QUIJOTE”}

El domingo 7 de mayo empezó la cobertura de los eventos conmemorativos en la prensa mexicana. Los corresponsales y editores de diferentes publicaciones periódicas documentaron las festividades en ambos lados del Atlántico. Por ejemplo, La Patria describió los eventos oficiales en Madrid: "La celebración de ese suceso honra a la madre patria, porque rinde el homenaje de su admiración al ilustre, al esclarecido ingenio español cuya fama repercute al través de las ciudades y de los pueblos". El reportero observó que los lectores americanos:

... somos admiradores del portentoso ingenio español, que vemos en su obra un perenne monumento de gloria y de arte, nos unimos al regocijo de los pueblos iberos que celebran hoy el centenario de que hablamos, como una manifestación pálida si se quiere, pero sincera de gratitud hacia el príncipe de los Ingenios ${ }^{21}$.

La revisión hemerográfica reveló que la prensa reportó activamente los festejos. Los editores recibieron cartas de corresponsales en Europa que informaron sobre las celebraciones, por ejemplo, la sección "Correspondencia Extranjera" de El Contemporáneo avisó que "Los festejos que celebran a España dicho al centenario de Don Quijote ocupan estos días a toda la prensa periódica"22. Por su parte, El abogado Cristiano Ilustrado ${ }^{23}$ reportó brevemente las fiestas en Madrid: "EL 8 DE MAYO, tercer centenario de la publicación de la obra inmortal de Cervantes fue observado cómo día de fiesta en toda España, habiendo juegos florales y descubrimiento de

\footnotetext{
21 Ibid., p. 1.

22 HNDM, "Correspondencia extranjera" en El Contemporáneo, 11/05/1905, pp. 1-2.

23 La publicación apareció todos los días primero de cada mes en la ciudad de México. En la hemeroteca existen copias desde el primero de agosto de 1880 hasta el 5 de diciembre de 1929. Su redactor en jefe fue Carlos G. Drees, se imprimió en la Imprenta Evangélica en Gante no. 5.
}

monumentos en honor del autor del Ingenioso Hidalgo Don Quijote de la Mancha"24.

Cabe destacar que El Correo Español afirmó ser el único periódico en tener un corresponsal en España. Su reporte de las festividades estuvo a cargo de Domingo Blanco: "enviado especial a las fiestas del Quijote". El periodista español trabajó en distintas publicaciones periódicas de Madrid y Salamanca: fue corresponsal en la Habana y, entre 1900 y 1901, vivió una temporada en México donde fue redactor de El Correo Español (Menéndez-Onrubia, 2017, p. 2). El 29 de mayo de 1905, la publicación mexicana divulgó su "relación de los festejos": "Estamos en plenas fiestas del Quijote. El programa no es muy notable ni mucho menos es digno de lo que se conmemora, pero lo que falta de festejos está de sobra compensado con el entusiasmo con que España entera se asociado a la patriótica conmemoración"25. El corresponsal puso atención en "la Fraternidad hispana que ha tenido la reunión en Madrid de todos los coros de la península", y en la gran divulgación que se ha hecho del libro de Cervantes. Confesó que nunca había sentido tan intenso patriotismo como el que le "produjo aquel coro de dos mil voces cantando el hermoso himno de gloria España”. Afirmó que en esa "ocasión han podido fundirse en un mismo amor catalanes y castellanos, gallegos y andaluces". Además, se impresionó por la gran cantidad de publicaciones que se imprimieron, y aseguró que "no quedará ningún español que ignore lo que es el Quijote y lo que fue su glorioso autor, el inmortal Cervantes". En su reporte, Domingo Blanco reseñó las conferencias en el Ateneo, las exposiciones de ediciones y grabados en la biblioteca nacional, "la batalla de las flores", la retreta organizada por los cuerpos de la Guardia Civil de Madrid y las conferencias académicas. Al final describió la concurrida procesión cívica "compuesta de más de cincuenta mil personas de todas las clases sociales" 26 .

Los festejos en España no fueron los únicos reportados en publicaciones mexicanas. La revisión hemerográfica arrojó notas que informaron sobre las con-

\footnotetext{
24 HNDM, "EL 8 DE MAYO” en El Abogado Cristiano Ilustrado, 18/05/1905, 5.

25 HNDM, “Desde Madrid” en El Correo Español, 29/05/1905, 1

26 Ibid., 1
} 
memoraciones en otras ciudades de México. Por ejemplo, El Tiempo ${ }^{27}$ reportó una velada en Mérida en honor a Cervantes organizada por "la agrupación de escritores". Los patrocinadores fueron el gobierno estatal, el Ayuntamiento y "la colonia española"28. Veracruz fue otro estado mexicano que realizó festividades para conmemorar el centenario. El periódico en inglés The Mexican Herald ${ }^{29}$ refirió un evento musical organizado en la capital del estado: "The colegio preparatorio of Jalapa, Veracruz, has organized a gran musical and literary entertainment to celebrate the appearance of the famous Don Quijote de La Mancha" ${ }^{30}$. En la ciudad de Orizaba se organizó una velada para celebrar la fecha, El Correo Español informó que la "Sociedad Sánchez Oropeza" festejó el tercer centenario de la publicación de "la inmortal obra de Cervantes". El orador oficial fue Rafael Delgado, "quien se trasladó a Orizaba después de haber tomado parte en otra velada que con el mismo fin se celebró en Jalapa" ${ }^{31}$. Otro estado mexicano que organizó celebraciones fue San Luis Potosí, en la Revista Positiva $^{32}$ apareció el texto titulado "En el Tercer Centenario del Quijote" firmado por el articulista Primo Feliciano Velázquez ${ }^{33}$. Se trató de un ensayo declamado en "las

27 El Tiempo circuló todos los días en la Ciudad de México desde el 24 de mayo de1883 hasta el primero de agosto de 1912. Su editor, propietario y director fue Victoriano Agüeros y su redacción estuvo en San Felipe de Jesús no. 2 .

28 HNDM, "El centenario de Cervantes EN MERIDA" en El Tiempo, $24 / 05 / 1905,2$

29 La publicación en lengua inglesa circuló en la Ciudad de México desde el 4 de octubre de 1895 hasta el primero de octubre de 1915. Su editor fue F. R. Guernsey y su director fue F. E. Young. Fue publicado por The Mexican Publishing Company en Coliseo Viejo no. 17

30 HNDM, "News of Mexico" en The Mexican Herald, 07/06/1905, 3

31 HNDM; "En Honor de Cervantes" en El Correo Español, 14/07/1905, 3

32 La revista apareció de manera irregular en la Ciudad de México, la hemeroteca digital resguarda copias desde el primero de enero de 1901 hasta el 3 de diciembre de 1914. El fundador fue Horacio Barrera y el editor fue Agustín Aragón.

33 Fue cofundador de los periódicos La Voz de San Luis y El Estandarte en San Luis Potosí. Miembro de la Academia Mexicana de la Lengua, de la Sociedad Mexicana de Geografía y Estadística y de la Academia Mexicana de la Historia. Su semblanza en sitio electrónico Cronologías de San Luis Potosí, refiere que su línea editorial causó polémica y promovió celebraciones como el nacimiento de Agustín de Iturbide. suntuosas y hermosísimas fiestas de San Luis Potosí". La revista copió informes en El Estandarte que reportaron una orquesta dirigida por el maestro Julián Carrillo; compuesta por profesores de música de la ciudad de México y "los más distinguidos de San Luis Potosi". Consignó que la sociedad de ese estado ha dado "muestras de una ilustración sólida que mucho la enaltece, y que nos sentimos orgullosos de vivir en una ciudad dechado de cultura y discreción"34.

La celebración en la Ciudad de México provocó la publicación de un número especial dedicado al tercer centenario de la primera edición del Quijote. El Tiempo Ilustrado ${ }^{35}$ divulgó un numero conmemorativo sobre los festejos en la capital mexicana, ahí Juan de Dios Peza preguntó: "¿Cómo rendir un tributo de admiración al padre de la lengua castellana en un periódico que se publica en la capital de la nación que por muchos años llamóse (sic) Nueva España?" Ratificó la admiración de las naciones que recuerdan a Cervantes, y escribió una introducción al ejemplar conmemorativo de la publicación:

Y entre todas las ofrendas que se depositan hoy en el altar de tu gloria, caiga está como la última, como la más pobre, pero que no deja de esconder en sus flores, matices de gratitud y aromas de ternura, para ti pobre manco que te hundiste en la sombra sin sospechar que al cabo de un siglo resucitarías en el Quijote para no volver a desaparecer nunca de la memoria, del respeto y de la admiración de los hombres ${ }^{36}$.

Los editores de El Tiempo Ilustrado avisaron que no podían dejar pasar "el centenario de la publicación del egregio libro": y ofrecieron 24 páginas ilustradas con fotograbados e impresas en papel "cuché".

34 HNDM, "En el tercer centenario del Quijote" en Revista Positiva, 05/11/1905, 24.

35 Fue un semanario que circuló en la Ciudad de México, aparece en la hemeroteca digital desde el 5 de julio de 1891 hasta 2 de junio de 1912. Se trató de la versión dominical de El Tiempo, hizo énfasis en su sección literaria y contó con ilustraciones, retratos, vistas y copias de cuadros famosos.

36 HNDM, "Nuestro homenaje a Cervantes" en El Tiempo Ilustrado, 21/05/1905, 2 
En su portada apareció con un bajorrelieve del Quijote, incluyó un facsímil de la primera edición y un retrato de Cervantes pues como refirió María Ángeles Chaparro Domínguez: "durante la celebración las imágenes de Miguel de Cervantes son tan populares como las de su valiente caballero manchego, o incluso más" (2012, p. 186). El número especial del El Tiempo Ilustrado ofreció grabados sobre las mujeres de la obra, el autógrafo del autor, una imagen de una calle de La Mancha, la representación de la prisión donde se supone se escribió la primera parte y el patio de la casa de Medrano. En cuanto a texto se distribuyeron escritos de Juan de Dios Peza, Manuel José Othón, José de Castro, Ventura de la Vega, Juan Montalvo, Federico Balart, Joaquín D. Casasús, José Sebastián Segura y Manuel G. Revilla. El precio del ejemplar fue de 25 centavos y gracias a su red de intermediarios se distribuyó en toda la República ${ }^{37}$.

En los meses posteriores a la celebración, las publicaciones centraron su atención en las premiaciones de los diferentes eventos, por ejemplo, La Patria cubrió el concurso en el conservatorio organizado por la Secretaría de Relaciones Exteriores. En esa ocasión se mencionó a los ganadores del certamen literario organizado por el Liceo Altamirano:

El lunes último se celebró en el Teatro del conservatorio, bajo la presidencia del distinguido secretario de Relaciones Exteriores licenciado don Ignacio Mariscal, una brillante velada, que organizó el licenciado Altamirano, para premiar en ella a los que vencieron en el torneo abierto por dicha agrupación, para celebrar el tercer centenario de la publicación del Ingenioso hidalgo Don Quijote de la Mancha, obra que perdurará al través de las edades como una de las más colosales producidas por humano ingenio ${ }^{38}$.

La nota señaló como vencedor a Victoriano Salado Álvarez, el distinguido hablista jalisciense". Se

37 HNDM, "El Tiempo Ilustrado. Número especial dedicado a Feriantes y al Quijote" en El Tiempo, 21/05/1905, 2.

38 HNDM, "La Semana” en La Patria, 20/08/1905, 1. aseguró que "su opúsculo "Influencia del Quijote en el pensamiento americano", debe ser calificado como una obra maestra. Se informó que otro premio lo obtuvo el trabajo del señor licenciado Rafael de Zayas Enríquez sobre "La mujer en las obras de Cervantes". En poesía se premió con 500 pesos al poema titulado "A Don Quijote" de Nemesio Naranjo y "Al Quijote" de Enrique Fernández Granados.:

Los triunfadores deben estar satisfechos (pues) han contribuido, con más de 40 escritos que entraron al concurso a elevar nuestra literatura, demostrando varias cosas, entre ellas que abundan en México intelectualidades conspicuas que saben honrar y rendir al ingenio y que en esta vez tratándose de la celebración del centenario de una obra española, la América Latina, ha demostrado su cariño por la madre España y ha estrechado los vínculos que la atan con la antigua metrópoli. ${ }^{39}$

Otro de los temas tratados en la cobertura de la prensa mexicana al tercer centenario del Quijote fueron las premiaciones en España. Por ejemplo, a fines de mayo, la prensa reportó los resultados de los concursos celebrados en Madrid. El Tiempo estuvo muy activo en este rubro, publicó entre otras cosas la crónica sobre la premiación de la lápida conmemorativa. El periódico avisó a los lectores que la obra fue construida por Lorenzo Coullaut Valera, y personifica a Don Quijote y a Sancho saliendo de la imprenta de Juan de la Cuesta ${ }^{40}$.

Cabe señalar que la mayoría de los eventos organizados en España y México recibieron buenas críticas en la prensa, aunque hay opiniones desfavorables a las celebraciones. Algunos articulistas no estuvieron conformes con los eventos organizados y utilizaron la prensa para expresar sus opiniones, como ejemplo, la nota en La Voz de México firmada por Christian: "Somos constantes enamorados de las apariencias. Somos los hombres de lo que brilla, de lo que deslumbra, y más aplausos merece de nuestras manos insensatas el que

\footnotetext{
39 Ibid., 1

40 HNDM. "Lápida conmemorativa” en El Tiempo, 26/05/1905, 1
} 
deleitándonos el oído con la voz y la vista con el gesto nos engaña". El autor se asumió como español y reprochó las celebraciones a Calderón de la Barca, las del descubrimiento de América y las del Quijote: "Nos damos con esas fiestas teatrales y aparatosas una especie de baño de porcelana para ocultar la negrura y aspereza de nuestro hierro viejo y mohoso". Aseguró que las celebraciones no estuvieron a la altura del genio de Cervantes pues:

$$
\text { | }
$$

... se han hecho algunas cosas bien intencionadas, otras ridículas y absurdas, otras vulgarísimas, y particularmente se han agotado en Ateneos, Academias y Certámenes los ingenios y las sabidurías para ponderar y enaltecer la obra de un hombre que en vida fue muy desgraciado, y que en muerte no cuenta con más que con la admiración universal, pero no con herederos que le honren en espíritu y en verdad.

Amonestó "las mascaradas insustanciales, las ceremonias frías y los discursos atiborrados de cansada erudición". Afirmó que como "los centenarios anteriores, no tendrá éste consecuencias para nuestro patriotismo que el haber lisonjeado pasajeramente el casi extinguido amor propio nacional", y añadió que "las nuevas generaciones" no ven en la obra la "enjundia cristiana, su sátira noble, honrada, razonable, la apología de la sensatez y del equilibrio de la fábula"41. En la prensa mexicana quedaron plasmadas las opiniones de editores, reporteros y lectores, como indicó Erick Storm: Cervantes y Don Quijote fueron reclamados por todas las corrientes ideológicas que subrayaron sus cualidades religiosas, lingüísticas, militares, psicológicas, jurídicas y poéticas (2008, p. 16).

Para la segunda mitad de 1905, las notas sobre las celebraciones al tercer centenario de la primera edición del Quijote se diluyen. La cobertura a los eventos deja de tener difusión en la prensa, aunque aparecen informes sobre los libros impresos a raíz de los concursos, por ejemplo, el Boletín de la Biblioteca Nacional de México informó oportunamente sobre los libros edita-

41 HNDM, "En espíritu y verdad" en La Voz de México, 04/06/1905, 1 dos en España que recibió para su colección ${ }^{42}$. En "Prácticas editoriales y recepción de la literatura española en Hispanoamérica (1833-1916)", Francisco Cuevas Cervera observó que la mayor parte de las veladas resultaron en libros de homenaje en todas las ciudades donde se llevaron a cabo festejos (2019, p. 7).

\section{CONCLUSIÓN}

Después de revisar el acervo de la Hemeroteca Digital Nacional de México (HNDM) se concluye que la prensa mexicana reportó casi al mismo tiempo que la española, la celebración al tercer centenario del El Ingenioso Hidalgo Don Quijote de la Mancha. Los editores de diarios, semanarios y revistas copiaron los reportes de publicaciones ibéricas y siguieron los preparativos de las distintas agrupaciones públicas y privadas. La prensa revela que algunas agrupaciones de españoles asentadas en las principales ciudades de América sirvieron como organizadores de veladas y patrocinadores de concursos, además, sus publicaciones periódicas hicieron una amplia cobertura antes, durante y después de los eventos. Sus corresponsales describieron los acontecimientos en España: se valieron de cartas y cables telegráficos para reportar los homenajes oficiales en Madrid a los lectores mexicanos. La información sobre las celebraciones en los diarios permeó entre los intelectuales mexicanos y diversas agrupaciones culturales se unieron a los festejos en distintas ciudades del país. La prensa también rindió tributo al libro español y se publicó un número conmemorativo en un periódico de circulación nacional. Aún falta revisar otras hemerotecas locales para ampliar y detallar la información sobre los eventos en distintos estados, aun así, se documentó cómo las publicaciones periódicas ayudaron a consolidar las aventuras del caballero de La Mancha entre intelectuales mexicanos de principios de siglo XX. I

42 HNDM, "Fernández Granados Enrique" en Boletín de la Biblioteca Nacional de México, 30/09/1905, 8 


\section{REFERENCIAS}

\section{ACERVOS DIGITALES}

» Hemeroteca Digital Nacional de México. http://www.hndm. unam.mx/index.php/es/

\section{BIBLIOGRAFÍA}

» Ayuso Pérez, A. (2007). La Ilustración Española y Americana ante el Tercer Centenario del Quijote. Espéculo: Revista de Estudios Literarios. http://webs.ucm.es/info/especulo/numero35/tricente. html

» Bazán de Huerta, M. (2015). El concurso del monumento a Cervantes en Madrid a partir de los proyectos redactados y su fortuna crítica. In J. Hernández Latas (Ed.), El arte público a través de su documentación gráfica y literaria homenaje a Manuel García Guatas. (pp. 55-74). Institución Fernando el Católico.

» Chaparro Domínguez, M. Á. (2009). La prensa española ante el IV Centenario de la publicación de la primera parte del Quijote (2005). Anales Cervantinos, XLI, 285-315. https://doi.org/10.3989/ anacervantinos.2009.014

» Chaparro Domínguez, M. Á. (2012). Las ilustraciones en la prensa española de 1905: estudio iconográfico de la cobertura del III centenario del Quijote. Textual \& Visual Media, 183-208. https:// textualvisualmedia.com/index.php/txtvmedia/article/view/57

» Cuevas Cervera, F. (2019). Prácticas editoriales y recepción de la literatura española en Hispanoamérica (1833-1916): observaciones sobre el corpus cervantino. Hipogrifo. Revista de literatura y cultura del Siglo de Oro, 1-12. https://www.redalyc.org/jatsRepo/5175/517560693049/517560693049.pdf

» Ferrándiz Lozano, J. (2004). El III centenario del Quijote en la prensa. Hoja de Lunes, pp. 6-7.

» González Cañal, R. (2016). Don Quijote de la Mancha en tierras americanas. Biblioteca Virtual Miguel de Cervantes, 205-214. http://www.cervantesvirtual.com/obra/don-quijote-de-la-mancha-en-tierras-americanas/

» Menéndez-Onrubia, C. (2017). Domingo Blanco Misamigo (Salamanca? - Madrid, 1943) [Semblanza]. Biblioteca Virtual Miguel de Cervantes, 1-5.

» Montero Reguera, J. (1997). El Quijote y la crítica contemporánea. Centro de Estudios Cervantinos.

» Pineda Franco, A. (2006). Más allá del interior modernista: El Rostro Porfiriano de la Revista Moderna (1903-1911). Revista Iberoamericana, LXXII (214), 155-169.

» Primo Feliciano Velázquez (2017). Cronologías de San Luis Potosí. http://cronologiassanluispotosi.com/primo-feliciano-velazquez.html

» Saborit, A. (2006). El Club Modernista. Relatos de una pasión americana. In A. Feros Carrasco \& R. Chartier, (eds.). Europa, América y el mundo: tiempos históricos (pp. 281-310). Marcial Pons.

» Storm, E. (2008). El Ateneo de Madrid y el tercer centenario del
Quijote en 1905. In N. Martínez de Castilla Muñoz (ed.), Don Quijote en el Ateneo de Madrid (pp. 11-47). Sociedad Estatal de Conmemoraciones.

» Storm, E. (2015). The Generation of 1898 and Cervantes: The invention of Don Quixote as a national symbol. In N. Achiri, Á. Baraibar, \& F. K. Schmelzer (Ed.), Actas del III Congreso Ibero-Africano de Hispanistas (pp. 361-372). Servicio de Publicaciones de la Universidad de Navarra. 